\title{
THE BLOCKING ACTION OF BACLOFEN ON EXCITATORY TRANSMISSION IN THE RAT HIPPOCAMPAL SLICE ${ }^{1}$
}

\author{
HANS-RUDOLF OLPE, ${ }^{2}$ MICHEL BAUDRY, LAURENT FAGNI, AND GARY LYNCH \\ Department of Psychobiology, University of California, Irvine, California 92717
}

Received September 16, 1981; Revised December 17, 1981; Accepted December 22, 1981

\begin{abstract}
The mode of action of baclofen on the physiology of the rat hippocampus was investigated by studying its effect on electrophysiological responses in the hippocampal slice preparation and by measuring biochemical parameters related to glutamate uptake, binding, and release.

Baclofen inhibited, in a dose-dependent fashion, the dendritic field potentials in field CA1 produced by stimulation of the Schaffer commissural fiber system. The drug was inactive in this respect at concentrations of 10 and $100 \mathrm{~nm}$ but consistently reduced the amplitude of both the dendritic field potential and the population spike at a concentration of $1 \mu \mathrm{M}$. At a concentration of $25 \mu \mathrm{M}$, baclofen virtually abolished the dendritic and cell body responses to afferent stimulation. Recovery of field potentials required between 7 and $10 \mathrm{~min}$ following the addition of $1 \mu \mathrm{M}$ baclofen.

The levorotatory form of baclofen was much more potent in suppressing synaptic responses than was the dextrorotatory enantiomer.

Baclofen, at a concentration of $5 \mu \mathrm{M}$, strongly antagonized the excitation of pyramidal neurons evoked by iontophoretically applied glutamate. The antagonism of the glutamate effect was much reduced when the slices were maintained in low calcium, high magnesium perfusion medium. Moreover, under low calcium conditions, baclofen did not interfere with the effects of bath-applied glutamate on antidromically elicited responses.

Baclofen did not affect the $\mathrm{Na}^{+}$-dependent or $\mathrm{Na}^{+}$-independent binding of $\left[{ }^{3} \mathrm{H}\right]$ glutamate to crude synaptic membrane fractions from the hippocampus. However, at a concentration of $1 \mu \mathrm{M}$, it markedly inhibited potassium-induced release of $\left[{ }^{3} \mathrm{H}\right]$ glutamate from hippocampal synaptosomes.

Taken together, the present results strongly suggest that baclofen suppresses synaptic responses in the Schaffer commissural fiber system of the hippocampus by blocking the release of an excitatory amino acid transmitter.
\end{abstract}

The mechanism and site of action of the antispastic agent baclofen (Lioresal) are still a matter of controversy. In view of its close structural resemblance to GABA, the drug was originally thought to be a GABA agonist. However, subsequent studies found that baclofen has a low affinity for GABA binding sites (Olsen et al., 1978) and that its depressant action on cell firing is not antagonized by bicuculline (Curtis et al., 1974). While it does not appear that baclofen exerts its physiological effects via the "classical" GABA receptors, recent work has suggested that it may interact with a novel, bicucullineinsensitive GABA binding site (Bowery et al., 1979). It

\footnotetext{
${ }^{1}$ This research was supported in part by Grant MH19793-10 from the National Institute of Mental Health and Grant AG00538 from the National Institute on Aging.

${ }^{2}$ To whom correspondence should be addressed at his permanent address: Ciba-Geigy Ltd., Pharmaceuticals Division, 4002 Basel, Switzerland.
}

was suggested that this receptor is involved in the regulation of transmitter release, and in support of this, GABA and baclofen were shown to inhibit the release of noradrenaline (Bowery et al., 1980). In a more recent study, however, Ault and Evans (1981) found baclofen to be inactive at noradrenergic synapses but to be a very potent inhibitor of neurotransmission in the hemisected spinal cord; these authors concluded that baclofen exerts its depressant action on spinal neurotransmission through inhibition of the release of excitatory amino acids (see also Fox et al., 1978, for similar arguments). A similar hypothesis has emerged from biochemical studies showing that baclofen blocks the release of several acidic amino acids from brain tissue (Potashner, 1978; Johnston et al., 1980).

A substantial body of evidence from several laboratories indicates that excitatory amino acids, and in particular glutamate, serve as neurotransmitters of the major synaptic systems in rat hippocampus (see Storm-Math- 
isen, 1977; Baudry and Lynch, 1981a, b, for reviews). The present experiments were intended first to identify the physiological actions of baclofen in the hippocampus and then to ascertain if these were correlated with effects on glutamate binding, uptake, and release. Since baclofen consists of a mixture of two enantiomers, with the $l$ form being active and the $d$ form being inactive (Olpe et al., 1978), the stereospecificity of the drug's effect was assessed.

The results strongly support the hypothesis that baclofen inhibits transmission by blocking the release of glutamate.

\section{Materials and Methods}

Electrophysiological experiments. Experiments were performed on male Sprague-Dawley rats weighing 180 to 250 gm (Simonsen Laboratories, Gilroy, CA). Hippocampal slices were prepared as described previously (Dunwiddie et al., 1978). The animals were killed by decapitation, and their brains were removed and transferred into pregassed medium $\left(4^{\circ} \mathrm{C}\right)$. The hippocampi were isolated carefully and cut into $400-\mu \mathrm{m}$-thick transverse slices using a Sorvall tissue chopper. The slices were placed on a nylon net located in a perfusion chamber as previously described (Spencer et al., 1976). The medium had the following composition: $\mathrm{NaCl}, 124 \mathrm{mM}$; $\mathrm{KCl}, 3.33$ $\mathrm{mm} ; \mathrm{KH}_{2} \mathrm{PO}_{4}, 1.25 \mathrm{~mm} ; \mathrm{MgSO}_{4}, 1.33 \mathrm{~mm} ; \mathrm{CaCl}_{2}, 3.13 \mathrm{~mm}$; $\mathrm{NaHCO}_{3}, 25.7 \mathrm{~mm}$; and D-glucose, $10 \mathrm{~mm}$. In some experiments, $\mathrm{CaCl}_{2}$ was omitted and an equimolar concentration of $\mathrm{MgSO}_{4}$ was substituted. The medium was pregassed with $95 \% \mathrm{O}_{2}, 5 \% \mathrm{CO}_{2}$ and its temperature was kept between 33 and $35^{\circ} \mathrm{C}$. The slices were kept in a static condition for $30 \mathrm{~min}$ with the medium level adjusted to their upper surface. They were subsequently superfused with gassed medium at a rate of $3.0 \mathrm{ml}$ ( 1 chamber volume) $/ \mathrm{min}$. Baclofen was dissolved in the medium and added by injection into the perfusion line. The drug was synthesized in the chemical laboratories of Ciba-Geigy Ltd., Basel.

Hippocampal slices were stimulated by means of twisted $120-\mu \mathrm{m}$ Nichrome wires placed under visual control either into the Schaffer commissural fiber system of the stratum radiatum (orthodromic activation) or on the alveus (antidromic stimulation). Glass micropipettes (impedance, 1 to 5 megohms) filled with $2 \mathrm{M} \mathrm{NaCl}$ were used for recording electrodes. One pipette was placed in the dendritic zone of the CA1 pyramidal cells, where it recorded the orthodromically elicited negative field potential representing the extracellular concomitants of the dendritic, excitatory postsynaptic potentials. A second electrode was placed in the pyramidal cell layer to record the orthodromic (population spike) or antidromic response of these cells evoked by stimulation of the Schaffer commissural fibers or of the alveus, respectively. Perfusion with baclofen at various concentrations (10 nM, $100 \mathrm{nM}$, and 1,5 , and $25 \mu \mathrm{M}$ ) was started when stable responses to orthodromic and antidromic stimulation were observed for a period of at least $5 \mathrm{~min}$. Drug perfusions lasted $5 \mathrm{~min}$ in all instances. Following the termination of drug delivery, recovery was observed for various periods of time. A drug was considered to be active only if its effect was fully reversible. Electrical stimulation of the slices was accomplished with monophasic $0.1-\mathrm{msec}$ pulses of 2 to $10 \mathrm{~V}$ delivered at a rate of $0.6 \mathrm{sec}^{-1}$. The signals were led into an averager or computer and plotted on a X-Y recorder. Typically, eight potentials were averaged.

In a second series of experiments, the action of baclofen $(5 \mu \mathrm{M})$ added to the perfusion medium on glutamateevoked excitation of pyramidal neurons was investigated. Pyramidal cells were activated by administering glutamate $(0.5 \mathrm{M})$ iontophoretically to the neurons' dendrites by means of single glass micropipettes. A retaining current of $20 \mathrm{nA}$ was used routinely. Glutamate was ejected repetitively at intervals of $1 \mathrm{~min}$ for periods of 3 to $5 \mathrm{sec}$ using currents of 2 to $30 \mathrm{nA}$. A glass micropipette placed in the cell body layer of stratum pyramidale of field CA1 recorded the action potentials of a single cell. The neurons were identified tentatively as pyramidal cells on the basis of their characteristic bursting pattern. The number of action potentials was recorded for each period of glutamate application using conventional techniques. Once constant responses to the ejection of glutamate were obtained, baclofen was added to the perfusion medium. These experiments were performed either in the presence or absence of calcium in the perfusion medium.

Biochemical experiments: $\left[{ }^{3} H\right]$ Glutamate binding, uptake, and release. Hippocampal membranes were prepared and immediately assayed for $\left[{ }^{3} \mathrm{H}\right]$ glutamate binding in the presence or absence of calcium as previously described (Baudry and Lynch, 1981a). High affinity $\left[{ }^{3} \mathrm{H}\right]$ glutamate uptake was measured on crude mitochondrial fractions according to the procedure of Sandoval et al. (1978) as described (Baudry and Lynch, 1981a). Calcium $(2.5 \mathrm{~mm})$ was included in the assay since Hill and Bowery (1981) report that baclofen binding is cation dependent. $\left[{ }^{3} \mathrm{H}\right]$ Glutamate release was evaluated by a modification of the method of Levy et al. (1974). Crude mitochondrial fractions from rat hippocampus were prepared by differential centrifugation. After resuspension in Krebs-Ringer bicarbonate buffer, synaptosomes were preloaded with $\mathrm{L}$ $\left[{ }^{3} \mathrm{H}\right]$ glutamate $(100 \mathrm{nM})$ by a $30-\mathrm{min}$ incubation at $37^{\circ} \mathrm{C}$ under a constant stream of $\mathrm{O}_{2}: \mathrm{CO}_{2}(95: 5)$ and then centrifuged at $10,000 \times g$ for $15 \mathrm{~min}$. The pellet was resuspended in oxygenated Krebs-Ringer bicarbonate buffer and aliquots were preincubated for $3 \mathrm{~min}$ at $37^{\circ} \mathrm{C}$ with or without $1 \mu \mathrm{M}$ baclofen. $\mathrm{K}^{+}(50 \mathrm{mM})$ then was added and the incubation continued for $3 \mathrm{~min}$. Free $\left[{ }^{3} \mathrm{H}\right]$ glutamate was separated from bound $\left[{ }^{3} \mathrm{H}\right]$ glutamate by rapid filtration on Millipore cellulose filters (pore size, $0.45 \mu \mathrm{m}$ ) and the radioactivity of both the filters and the filtrates was measured by liquid scintillation spectrophotometry.

\section{Results}

Effect of baclofen on electrophysiological responses. Baclofen at a concentration of $1 \mu \mathrm{M}(n=5)$ markedly inhibited the size of the population spike and consistently reduced the amplitude of the dendritic field potential evoked by stimulation of the Schaffer commissural system (Fig. 1, $a$ and $b$ ). No significant effect on either response was detected with concentrations of $10 \mathrm{nM}(n$ $=2$ ) or $100 \mathrm{nM}(n=4$; data not shown). At a concentration of $1 \mu \mathrm{M}$, the onset of action occurred 2 to $2.5 \mathrm{~min}$ after the start of perfusion. At this drug concentration, full 
recovery was observed 7 to $10 \mathrm{~min}$ after the 5 -min perfusion. At a concentration of $25 \mu \mathrm{M}$, the dendritic response was reduced by more than $50 \%$ (Fig. $1 d$ ) and the population spike was eliminated (Fig. $1 \mathrm{c}$ ). Recovery was seen 60 to 90 min after termination of the perfusion with the drug $(n=2)$. The amplitude of the antidromically elicited negative field potential recorded in the pyramidal cell layer was not affected at concentrations of $1(n=2)$, $5(n=3)$, or $25 \mu \mathrm{M}(n=1)$ during a 5 -min perfusion (data not shown).

In order to assess the stereoselectivity of the depressant action of baclofen, slices were perfused for $5 \mathrm{~min}$

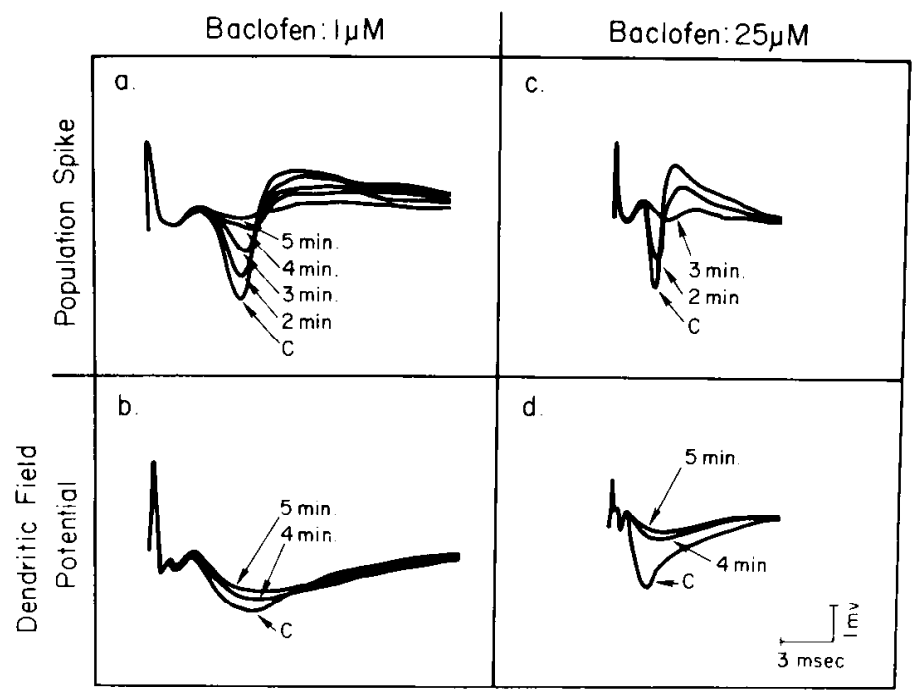

Figure 1. Effect of baclofen on the dendritic field potential and population spike. Population spike and dendritic field potentials evoked by stimulation of the Schaffer commissural fiber system were recorded at various times following perfusion of the slices with 1 ( $a$ and $b$ ) or $25 \mu \mathrm{M}$ ( $c$ and $d$ ) baclofen. $C$ refers to predrug responses. Each trace is the average of eight responses obtained at $0.6 \mathrm{sec}^{-1}$. with various concentrations of either the levorotatory or the dextrorotatory enantiomer of baclofen. The levorotatory enantiomer of baclofen at a concentration of $1 \mu \mathrm{M}$ markedly reduced the size of the population spike and of the dendritic response (Fig. 2, $a$ and $b ; n=3$ ). By contrast, at concentrations of $5 \mu \mathrm{M}$, the dextrorotatory form of baclofen had no effect on the two types of responses (Fig. 2, $c$ and $d ; n=4$ ). While the levorotatory enantiomer of baclofen at a concentration of $25 \mu \mathrm{M}$ strongly reduced the dendritic field potentials and completely suppressed the population spike, the dextrorotatory enantiomer only minimally affected the size of these potentials at this concentration (Fig. 2 , $e$ and $f ; n=3$ ).

The action of baclofen $(5 \mu \mathrm{M})$ on the glutamate-induced excitation of pyramidal neurons was investigated on 12 neurons in $\mathrm{Ca}^{2+}$-free medium and on 9 neurons in $\mathrm{Ca}^{2+}$. containing medium. Baclofen reduced the glutamate-induced excitation of pyramidal neurons by about $60 \%$ under normal medium conditions (Fig. 3). Recovery from this effect was seen about 4 min after the end of the perfusion with the drug. By contrast, in the absence of $\mathrm{Ca}^{2+}$ ions and in the presence of an increased $\mathrm{Mg}^{2+}$ concentration, the same concentration of baclofen $(5 \mu \mathrm{M})$ only marginally affected the responsiveness of pyramidal cells to glutamate (Fig. 3).

As a further test of the possible postsynaptic actions of baclofen, the effects of the drug on glutamate-induced changes in antidromic responses elicited by stimulation of the alveus were tested under low calcium, high magnesium conditions. Figure 4 illustrates the results of a typical experiment. Glutamate ( $1 \mathrm{~mm}$ ) was added to the perfusion line and produced a rapid, replicable, and fully reversible reduction in the size of the antidromic response. Baclofen exerted no measurable effects on the antidromic response or on the glutamate-induced reduction of the response (see Table I).

Biochemical studies of baclofen on glutamate uptake, binding, and release. In order to assess the possible site

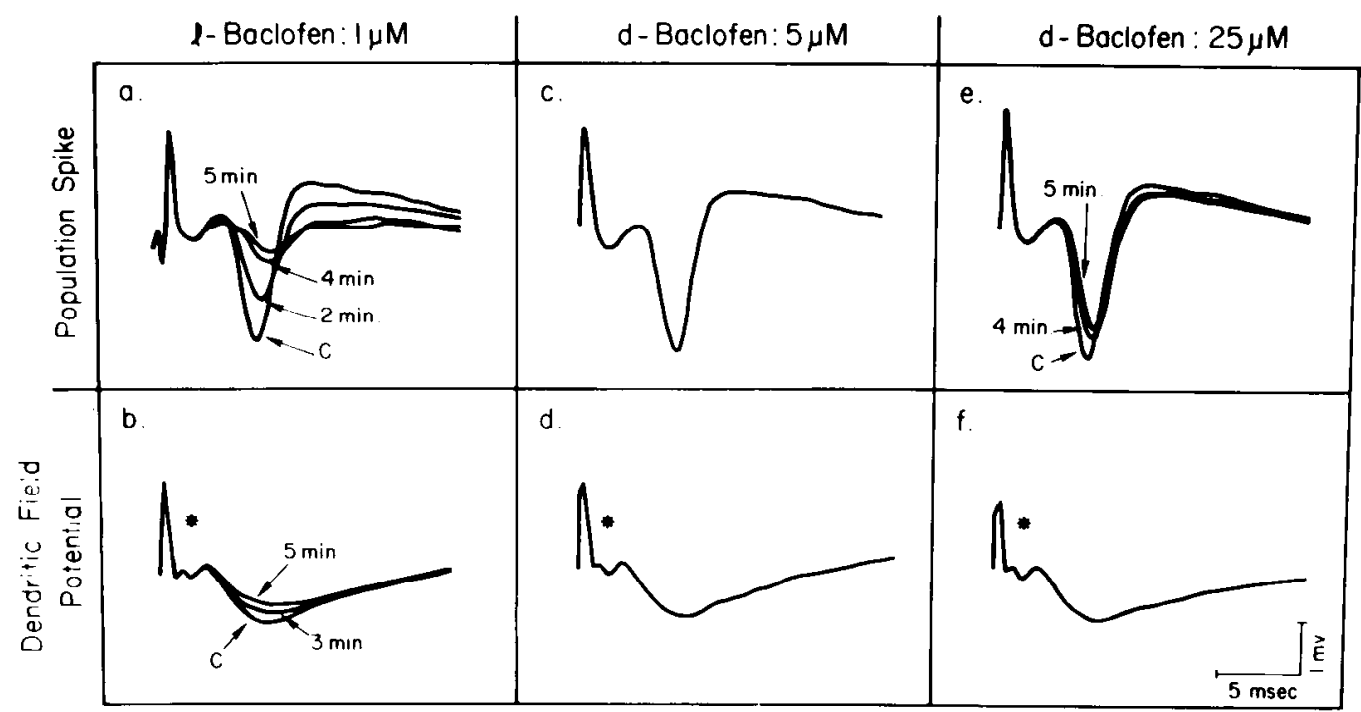

Figure 2. Stereospecificity of the depressant action of baclofen. Population spike and dendritic field potential evoked by stimulation of the Schaffer commissural fiber system were recorded at various times following perfusion of the slices with: $1 \mu \mathrm{M} l$-baclofen ( $a$ and $b$ ), $5 \mu \mathrm{M} d$-baclofen $(c$ and $d$ ), and $25 \mu \mathrm{M} d$-baclofen ( $e$ and $f$ ). The asterisks indicate the fiber volley. $c, d$, and $f$ are responses obtained after 5 min of perfusion with the respective drugs. 


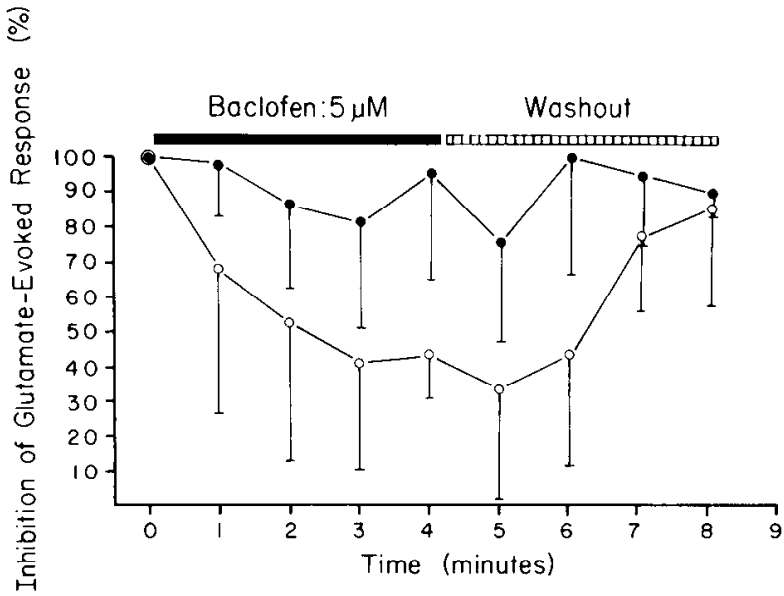

Figure 3. Effect of baclofen on glutamate-induced neuronal activation in the presence or absence of calcium. Pyramidal cells were activated by microiontophoretic administration of glutamate ( 3 to $5 \mathrm{sec}, 2$ to $30 \mathrm{nA}$ ) onto their dendrites at intervals of $1 \mathrm{~min}$. The number of spikes recorded from individual neurons during each period of glutamate application was determined. The results are expressed as a percentage of the average activity measured during two or three predrug control recordings. The perfusion with baclofen lasted $4 \mathrm{~min}$ and was followed by a 4-min washout period. The effect of baclofen was determined in the presence of calcium $(0 ; n=9)$ or in the absence of calcium $(0 ; n=11)$. Each trace is the average of eight responses obtained at $0.8 \mathrm{sec}^{-1}$. Each data point represents the mean \pm SEM of 9 or 11 experiments.

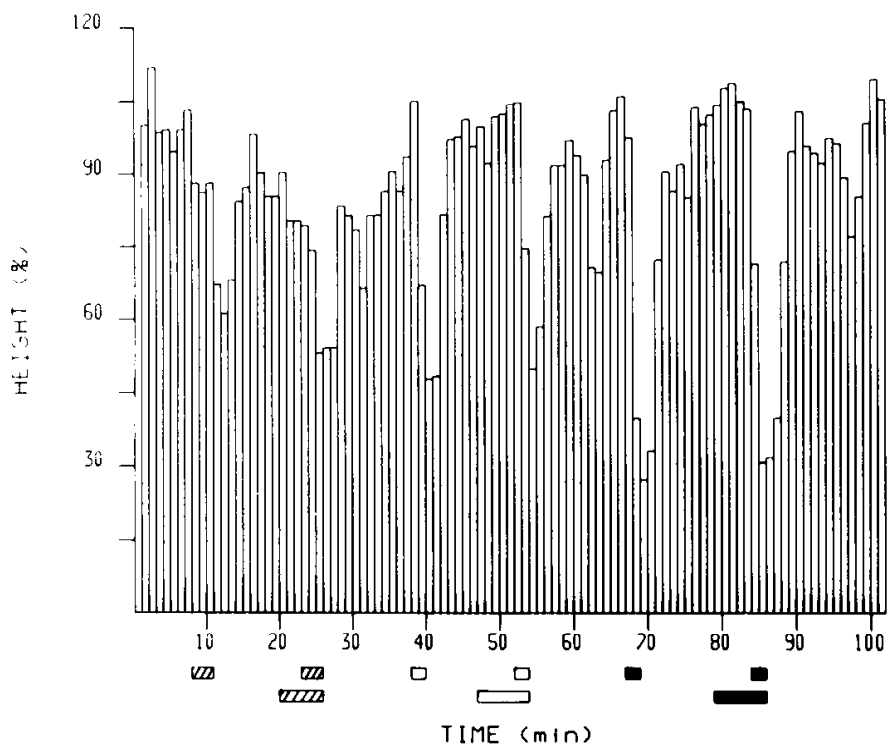

Figure 4. Effect of baclofen on glutamate-induced reduction of the antidromic potential in the absence of calcium. The antidromic field potential evoked by stimulation of the alveus was recorded in the CA1 pyramidal field in slices continuously perfused with a calcium-free medium. Three- to 5-min pulses of various concentrations of glutamate were applied (upper level of boxes) without or with pretreatment with various concentrations of baclofen (lower level). The results (mean of 2 experiments) are expressed as the percentage of the average amplitude of the potential measured for 10 to $15 \mathrm{~min}$ before starting the drug perfusions. Hatched bars, $0.5 \mathrm{~mm}$ glutamate, $5 \mu \mathrm{M}$ baclofen; open bars, $1 \mathrm{mM}$ glutamate, $10 \mu \mathrm{M}$ baclofen; solid bars, $2 \mathrm{~mm}$ glutamate, $15 \mu \mathrm{M}$ baclofen. of action of baclofen in the hippocampus, we measured its effect on several biochemical markers of glutamatergic synapses. The sodium-independent $\left[{ }^{3} \mathrm{H}\right]$ glutamate binding site has been shown to have properties expected of a postsynaptic glutamate receptor, while the sodium-dependent binding site appears to be associated with high affinity uptake sites (Baudry and Lynch, 1981a, b). Baclofen, in the range $0.1 \mu \mathrm{M}$ to $0.1 \mathrm{mM}$, was totally devoid of effect on the sodium-independent $\left[{ }^{3} \mathrm{H}\right]$ glutamate binding as well as on the calcium-induced stimulation of $\left[{ }^{3} \mathrm{H}\right]$ glutamate binding (Baudry and Lynch, 1981b) to crude synaptic membranes from hippocampus. Similarly, baclofen, in the same range of concentrations, did not modify the sodium-dependent $\left[{ }^{3} \mathrm{H}\right]$ glutamate binding to hippocampal synaptic membranes nor the high affinity uptake of $\left[{ }^{3} \mathrm{H}\right]$ glutamate by hippocampal synaptosomes. On the other hand, the drug quite significantly reduced the $\mathrm{K}^{+}$evoked release of $\left[{ }^{3} \mathrm{H}\right]$ glutamate from hippocampal synaptosomes (Table II). Concentrations of baclofen as low as $1 \mu \mathrm{M}$ inhibited the $\mathrm{K}^{+}$-evoked release of $\left[{ }^{3} \mathrm{H}\right.$ ]glutamate by about $50 \%$, whereas it had no effect on the spontaneous release of preloaded $\left[{ }^{3} \mathrm{H}\right]$ glutamate.

\section{Discussion}

Baclofen, in a stereospecific fashion, produces a rapid and reversible suppression of the monosynaptic re-

TABLE I

Effect of glutamate and baclofen on the antidromic field potential in the CAl pyramidal field

The data were obtained from the experiments illustrated in Figure 4. For the effects of baclofen, the results are expressed as ratios of the amplitude of the potential during and before the period of baclofen perfusion. For the effects of glutamate, the results represent the maximal decrease elicited by glutamate as a percentage of the average amplitude of the potential recorded during the 10 to $15 \mathrm{~min}$ before starting the drug perfusions. The values represent the mean \pm SEM of 4 to 6 experiments.

\begin{tabular}{lrccc}
\hline & \multicolumn{4}{c}{ Baclofen } \\
\cline { 2 - 4 } Glutamate & \multicolumn{1}{c}{0} & $5 \mu \mathrm{M}$ & $10 \mu \mathrm{M}$ & $15 \mu \mathrm{M}$ \\
\hline$m_{\mathrm{M}}$ & & & & \\
0 & $100 \pm 5$ & $112 \pm 10$ & $108 \pm 6$ & $98 \pm 8$ \\
0.5 & $54 \pm 8$ & $49 \pm 6$ & & \\
1.0 & $41 \pm 8$ & & $49 \pm 7$ & \\
2.0 & $27 \pm 4$ & & & $29 \pm 6$ \\
\hline
\end{tabular}

TABLE II

Effect of baclofen $(1 \mu \mathrm{M})$ on $\mathrm{K}^{+}$.evoked $\left[{ }^{3} \mathrm{H}\right] \mathrm{glutamate}$ release from hippocampal synaptosomes

Hippocampal synaptosomes were prepared by differential centrifugation. After a preloading period with [ $\left.{ }^{3} \mathrm{H}\right]$ glutamate $(100 \mathrm{nM})$ followed by centrifugation, synaptosomes were preincubated for $3 \mathrm{~min}$ at $37^{\circ} \mathrm{C}$ with or without $1 \mu \mathrm{M}$ baclofen. Basal or $\mathrm{K}^{\prime}$-evoked $\left[{ }^{3} \mathrm{H}\right]$ glutamate release was determined by a further 3 -min incubation, with or without $50 \mathrm{~mm} \mathrm{KCl}$, followed by filtration on Millipore filters. The results (mean \pm SEM) are expressed as the ratios of the radioactivity found in the filtrate over that found in the corresponding filter.

\begin{tabular}{lccc}
\hline & Basal & $\mathrm{K}^{+}(50 \mathrm{~mm})$ & Percent \\
\hline Control (12) & $0.60 \pm 0.03$ & $1.14 \pm 0.04$ & 90 \\
Baclofen (12) & $0.60 \pm 0.04$ & $0.93 \pm 0.04^{\prime \prime}$ & 55
\end{tabular}

"Number of experiments.

" $p<0.01$ as compared to the $\mathrm{K}^{+}$-evoked release in the absence of baclofen (Student's $t$ test). 
sponses of the CA1 pyramidal cell dendrites to their Schaffer commissural afferents. In a paper which appeared while this communication was under review, Ianthorn and Cotman (1981) report that baclofen depresses this response. The drug also causes a pronounced inhibition of the increase in cell firing produced by glutamate applied iontophoretically to the dendrites. This effect occurred in the absence of detectable changes in the size of either population antidromic responses or individual cell spikes. Since these latter two measures are sensitive to resting membrane potential, it is unlikely that baclofen causes a generalized (i.e., cell-wide) depolarization or hyperpolarization. An effect of the drug on a dendritic ion conductance channel could reduce transmission and glutanate-induced excilation (e.g., by a shunting action) and possibly reduce cell spiking by interfering with the postsynaptic effects of spontaneously released transmitter from the Schaffer commissural terminals. A blocking action on glutamate receptors also would accomplish this effect. Alternatively, and as has been suggested previously, baclofen may block the release of the excitatory transmitter utilized by the Schaffer commissural afferents.

Several aspects of the present findings support this latter interpretation. First, the suppression of glutamateinduced cell firing produced by baclofen was greatly reduced when the slices were perfused with low calcium, high magnesium media. The simplest interpretation of this finding is that iontophoretically applied glutamate stimulates the pyramidal cells by promoting release from the Schaffer commissural afferents (by depolarizing the terminals) and by acting directly on the target dendrites and that baclofen inhibits the first of these two effects. Further support for the hypothesis that baclofen does not interfere with the postsynaptic actions of glutamate was obtained in experiments in which amino acid was perfused into the slices under low calcium conditions. Baclofen by itself did not alter antidromic responses detectably in these experiments nor did it antagonize the marked depression of the response produced by brief pulses of glutamate. This result accords well with the finding of Ault and Evans (1981) that baclofen blocked glutamate-induced depolarization of spinal motoneurons in the presence, but not in the absence, of synaptic transmission. While it is possible that the baclofen binding site has a strong calcium requirement, biochemical experiments have shown that the drug binds equally well in the presence of calcium or magnesium (Hill and Bowery, 1981) and the reduced calcium in our experiment was balanced by increased magnesium. Finally, the biochemical experiments provided direct evidence that baclofen does block the release of excilatory anino acids. The drug was found to have no effects, even at high concentrations, on the sodium-dependent and sodiumindependent binding of glutamate nor did it detectably influence high affinity glutamate uptake. However, at physiologically effective concentrations, baclofen did block potassium-induced release of preloaded $\left[{ }^{3} \mathrm{H}\right]$ glutamate.

As mentioned, a substantial body of evidence suggests that glutamate, or a closely related compound, is the transmitter utilized by the Schaffer commissural projec- tions. Our conclusion that baclofen acts presynaptically to block release from these terminals is in agreement with previous studies which indicate a similar mode of action of the compound in suspected glutamatergic terminals in the spinal cord (Davidoff and Sears, 1974; Fox et al., 1978; Ault and Evans, 1981). It also has been found that baclofen blocks the release of amino acid agonists from cortical slices without interfering with GABA release (Potashner, 1978). However, while there is ample reason to assume that the depressant effects of the drug on release are not universal (Ault and Evans, 1981; Potashner, 1978), it would be premature to conclude that baclofen acts only on synapses utilizing glutamic acid as a transmitter.

\section{References}

Ault, B., and R. H. Evans (1981) The depressant action of baclofen on the isolated spinal cord of the neonatal rat. Eur. J. Pharmacol. 71: 357-364.

Baudry, M., and G. Lynch (1981a) Characterization of two ${ }^{3} \mathrm{H}$ glutamate binding sites in rat hippocampal membranes. J. Neurochem. 36: 811-820.

Baudry, M., and G. Lynch (1981b) Hippocampal glutamate receptors. Mol. Cell Biochem. 38: 5-18.

Bowery, N. G., A. Doble, D. R. Hill, A. L. Hudson, T. S. Shaw, and M. J. Turnbull (1979) Baclofen: A selective agonist for a novel type of GABA receptor. Br. J. Pharmacol. 67: 444.

Bowery, N. G., D. R. Hill, A. L. Hudson, A. Doble, D. N. Middlemiss, T. Shaw, and M. Turnhull (1980) Raclofen decreases neurotransmitter release in the mammalian CNS by an action at a novel GABA receptor. Nature 283: 92-94.

Curtis, D. R., C. J. A. Game, G. A. R. Johnston, and R. M. McCulloch (1974) Central effects of $\beta$-( $p$-chlorophenyl)- $\gamma$ aminobutyric acid. Brain Res. 70: 493-499.

Davidoff, R. A., and M. D. Sears (1974) The effects of Lioresal on synaptic activity in the isolated spinal cord. Neurology (N. Y.) 24: 957-963.

Dunwiddie, T., V. Madison, and G. Lynch (1978) Synaptic transmission is required for initiation of long-term potentiation. Brain Res. 150: 413-417.

Fox, S., M. E. Morris, E. Puil, and R. Werman (1978) Action of baclofen on mammalian synaptic transmission. Neuroscience 3: 495-515.

Hill, D. R., and N. G. Bowery (1981) ${ }^{3} \mathrm{H}$-Baclofen and ${ }^{3} \mathrm{H}-\mathrm{GABA}$ bind to bicuculline-insensitive $\mathrm{GABA}^{\mathrm{B}}$ sites in rat brain. Nature 290: 149-152.

Johnston, G. A. R., M. H. Hailstone, and C. G. Freeman (1980) Baclofen: Stereoselective inhibition of excitant amino acid release. J. Pharm. Pharmacol. 32: 230-231.

Lanthorn, 'T. H., and C. W. Cotman (1981) Baclofen selectively inhibits excitatory synaptic transmission in the hippocampus. Brain Res. 225: 171-178.

Levy, W. B., J. W. Haycock, and C. W. Cotman (1974) Effects of polyvalent cations on stimulus-coupled secretion of ${ }^{14} \mathrm{C}-\gamma$ aminobutyric acid from brain synaptosomes. Mol. Pharmacol. 10: 438-449.

Olpe, H. -R., H. Demieville, V. Baltzer, W. L. Bencze, W. P. Koella, P. Wolf, and H. L. Haas (1978) The biological activity of $d$ - and $l$-baclofen (Lioresal). Eur. J. Pharmacol. 52: 133136.

Olsen, R. W., M. K. Tichu, P. C. Van Ness, and D. Greenlee (1978) Effects of drug on $\gamma$-aminobutyric acid receptors, uptake, release and synthesis in vitro. Brain Res. 139: 277-294.

Potashner, S. J. (1978) Baclofen: Effects on amino acid release. Can. J. Physiol. Pharmacol. 56: 150-154.

Sandoval, M. E., P. Horch, and C. W. Cotman (1978) Evaluation 
of glutamate as a hippocampal neurotransmitter: Glutamate uptake and release from synaptosomes. Brain Res. 142: 285299.

Spencer, H., V. K. Gribkoff, C. W. Cotman, and G. S. Lynch (1976) GDEE antagonism of iontophoretic amino acid exci- tations in the intact hippocampus and in the hippocampal slice preparation. Brain Res. 105: 471-481.

Storm-Mathisen, J. (1977) Localization of transmitter candidates in the brain: The hippocampal formation as a model. Prog. Neurobiol. 8: 119-181. 